\title{
Accidents and Adverse Effects
}

National Cancer Institute

\section{Source}

National Cancer Institute. Accidents and Adverse Effects. NCI Thesaurus. Code C105736.

Causes of death attributable to accidents or their adverse events. 